\title{
ANIMAL AND HUMAN EMOTIONS IN AN EVOLUTIONARY CONTEXT
}

\section{Kellie Sara Duffett Carlson}

Department of Evolutionary Anthropology, Centre for Organismal Systems Biology, University of Vienna, Vienna, Austria.

kelliesard86@univie.ac.at

A Review of the Book

\section{Not So Different: Finding Human Nature in Animals}

By Nathan H. Lents. 2016.

Columbia University Press, New York. 349 pages.

ISBN 978-0-231-17832-7 (Hardback, \$35.00, USD)

Nathan Lents is Full Professor of Biology and Director of the Honors College at CUNY's John Jay College of Criminal Justice, New York. He specialises in molecular biology, forensic DNA, and evolution. As a science communicator and blogger, Lents focusses on the effects of evolution on the human mind and body. He has authored two popular science books, the first of which, Not So Different, is reviewed here.

Of late several popular science books have been authored that discuss proposed similarities shared by animals and humans. These books, in one way or another, discuss the contentious and interrelated topics of the emotional lives and cognitive capacities of social animals. Although the topic is not new, having been addressed by Darwin in 1872, research is increasingly providing convincing evidence for complex animal cognition, and as Lents argues, for complex social lives that manifest in rather human-like ways, such as compassion in gorillas and chimps, jealous rages in tigers, greed in wolverines, and guilt both in domesticated dogs and wild wolves. The aim of this book is not simply to enumerate these similarities but to hypothesise why they should exist. Perhaps taking a cue from Dobzhansky's (1973) famous essay, Lents contends that the reason is evolution. Not So Different focusses on what Lents proposes are, in brief, shared biological underpinnings encoded by genes, some with deep evolutionary roots, that are 
at least in part, the basis for many behaviours and emotions shared by animals and humans. That blueprint is fine-tuned for each species by its evolutionary history.

In ten well-researched chapters, Lents covers a broad variety of topics: the existence and functions of play, justice, morality, sexual politics, love, grief, jealousy, greed, power, and fear in the animal world. He does this by distilling scientific research into explanations that are accessible to the lay reader. While other books focus on one animal or genus in particular, Lents explores numerous fascinating examples from widely diverse species, including rodents, dolphins, primates, and dogs. Experiments using animal models are presented throughout the text and juxtaposed with human behaviours. However, this is not a book about human evolutionary psychology. It is not until chapter nine that Lents mentions psychoevolutionary theory at all, and only to reiterate the idea that certain basic emotions, such as fear, stress, and despair, "form a suite of very simple and very ancient emotional programs shared by all or most vertebrates, especially mammals"(p. 246). Though Lents states that the impetus for the book is founded on his belief that understanding the similarities and differences between human and animal behaviours in an evolutionary context can provide a framework for addressing why humans are the way they are, the focus is on the identification and acceptance of animal emotions, not on explaining human ones.

Lents is not alone in identifying, for example, reciprocal altruism or jealousy in animals; evidence is provided from peer-reviewed literature wherein the authors of the individual studies diagnose these behaviours and emotions in their test subjects. Lents accumulates these varied data to make the point that, when considered together, they offer ever-increasing evidence for what he is labelling as emotion. He argues that it is more parsimonious to refer to these behaviours, which manifest similarly in both animals and humans as such than to suggest animals merely behave as though they have emotions. Behaviours are, in sum, evolutionarily calibrated phenotypes, and like many phenotypes, such as the digits of the mammalian forelimb, humans share some with other social animals. "In different habitats and lifestyles, natural selection has shaped these digits into fingers, paws, hooves, fins, and wings....The same anatomical digits are the common underlying chassis of those wildly different structures. Similarly, behavioral programs are like templates that can be modified in different lineages based on the adaptive pressures experienced in a specific time and place" (p. 237).

It is important to note that although Lents approaches ethology, and human psychology and sociology through an evolutionary lens, his thesis is not based in rigid biological determinism. He acknowledges that human behaviours and emotions are also culturally mediated. In fact, Lents is careful not to mislead any reader hoping either to equate all animal behaviour with human behaviour, or to use evolution as an apology for unethical human behaviour. Moreover, the thesis is not the result of uncritical anthropomorphising. Although he introduces topics with anecdotal evidence via personal stories in which anthropomorphism plays a role, ostensibly for the purpose of making the more scholarly content accessible, his arguments are supported by empirical evidence.

One of the most valuable of the book's lessons is that we acknowledge how our approaches to data (in this case animal behaviours), and how we frame our questions and choose our definitions, affect our hypotheses and thus also the conclusions we draw from our results. Lents convincingly argues via a multitude of studies, that animals 
having emotions is a prudent explanation for many of the behaviours they display. To accept that a given animal experiences a given emotion is anthropomorphism only if we frame emotions as something exclusively experienced by humans. For instance, early in the first chapter, he makes the important point that if we define play as play for the sake of play alone, we will not find other reasons for it because we have chosen to exclude other reasons from the definition. Similarly, he wonders why same-sex relations were not identified in nonhuman species until recently. His answer is that, if we are not looking for something, then we surely will not find it; if we label same-sex behaviours in animals as, for example, dominance displays, then we will never find same-sex activity, only dominance displays. This is an important lesson for all researchers, including those in my field researching behavioural and anatomical modernity in the Pleistocene archaeological and fossil records.

The danger of any meta-study, especially one that encompasses such a wide variety of topics in such an evolutionarily and behaviourally diverse group of animal taxa, is that it is impossible for the author to critically choose sources with the same level of scrutiny as an expert in any one of the many subfields that are explored. Generalisations will be made, and contentious topics simplified; the expert in any given field may find fault with a small piece of information, perhaps because the topic itself is controversial, or because a piece of data was omitted. For example, as an evolutionary anthropologist, I disagree with the assertion that most anthropologists believe Neandertal burials were for purely practical purposes. In fact, we continue to argue about evidence for deliberate inhumation and its symbolic significance (Dibble, et al., 2015; Rendu, et al., 2014, 2016; Zilhão, 2015). And though Lents questions whether a Pleistocene forager would put the same level of effort into the care of a suffering friend as do captive chimps, new research assessing potential evidence for conspecific care in human prehistory suggests that they just might have (Hublin, 2009; Spikins, et al., 2018; Tilley, 2015). Moreover, the notions of behavioural modernity and primitivity, as mentioned in chapter ten are increasingly being replaced with a view that more closely resembles how we view genetic clines; behaviours lie on a spectrum as do anatomical traits; these manifest differently at different times and cannot be neatly sorted into discrete packages. In fairness, however, these sorts of omissions are inevitable, and such mistakes small, and at least as concerns my own bailiwick, evolutionary anthropology, few in number. They do not detract from the cogency of his arguments nor the persuasiveness of the overall thesis. In fact, identifying an evolutionary legacy of complex cognition and its attendant emotional states in Pleistocene Homo would potentially strengthen his argument.

Not So Different is a well-written, well-edited, and entertaining book that manages to steer clear of many of the more contentious aspects of evolutionary psychology (wisely, given the book is about animals, not humans). Ethologists and cognitive scientists whose work focusses on one particular genus will find thought provoking parallels between the behaviours of their subjects and those of animals on more distant evolutionary branches. Animal enthusiasts and pet owners will also find delightfully relatable anecdotes introducing complex topics, which will stimulate further interest in ethology, evolution, and cognitive science. 


\section{ABOUT THE AUTHOR}

Kellie Sara Duffett Carlson is a $\mathrm{PhD}$ candidate in Biology in the Department of Evolutionary Anthropology at University of Vienna, and a technician in the Pinhasi aDNA Lab. Her research focusses on functional morphology, orofacial bone biology, and dietary adaptation.

\section{REFERENCES}

Darwin, C. (1872). The Expression of the Emotions in Man and Animals. London, UK: John Murray. DOI

Dibble, H., Aldeias, V., Goldberg, P., McPherron, SP., Sandgathe, D., \& Steele, TE. (2015). A critical look at evidence from La Chapelle-aux-Saints supporting an intentional Neandertal burial. Journal of Archaeological Science, 53, 649-657. DOI

Dobzhansky, T. (1973). Nothing in biology makes sense except in light of evolution. American Biology Teacher, 35(3), 125-129. DOI

Hublin, J-J. (2009). The prehistory of compassion. Proceedings of the National Academy of Sciences, 106(16), 6429-6430. DOI

Rendu, W., Beauval, C., Crevecoeur, I., Bayle, P., Balzeau, A., Bismuth, T., Bourguignon, L., Delfour, G., Faivre, J-P., Lacrampe-Cuyaybère, F., Tavormina, C., Todisco, D., Turq, A., \& Maureille, B. (2014). Evidence supporting an intentional Neandertal burial at La Chapelle-aux-Saints. Proceedings of the National Academy of Sciences, 111(1), 81-86. $\underline{\mathrm{DOI}}$

Rendu, W., Beauval, C., Crevecoeur, I., Bayle, P., Balzeau, A., Bismuth, T., Bourguignon, L., Delfour,G., Faivre, J-P., Lacrampe-Cuyaybère, F., Muth, X., Pasty, S., Semal, P., Tavormina, C., Todisco, D., Turq, A., \& Maureille, B. (2016). Let the dead speak... comments on Dibble et al.s reply to "Evidence supporting an intentional Neandertal burial at La Chapelle-aux-Saints”. Journal of Archaeological Science, 69(2), 12-20. DOI

Spikins, P., Needham, A., Tilley, L., \& Hitchens, G. (2018). Calculated or caring? Neanderthal healthcare in social context. World Archaeology, pp. 1-20. DOI

Tilley, L. (2015). Accommodating difference in the prehistoric past: revisiting the case of Romito 2 from a bioarchaeology of care perspective. International Journal of Paleopathology, 8, 64-74. DOI

Zilhão, J. (2015). Lower and Middle Palaeolithic behaviours and the origins of ritual burial. In C. Renfrew, M.J. Boyd, \& I. Morely (Eds.), Death Rituals, Social Order and the Archaeology of Immortality in the Ancient World. 'Death Shall Have No Dominion' (pp. 27-44). Cambridge, UK: Cambridge University Press. DOI 